\title{
Adaptation energy: Experimental evidence and applications in exercise science
}

\author{
Ecaterina Vasenina, Ryo Kataoka, and Samuel L Buckner
}

\begin{abstract}
Adaptation energy was proposed by Hans Selye as a working hypothesis to explain the exhaustion phase of the general adaptation syndrome (GAS), which resulted in loss of adaptation and death following exposure to various noxious agents (e.g., morphine, atropine, formaldehyde) in rodents. Despite being the mechanistic explanation behind his experimental findings, Selye was inconsistent in defining what "adaptation energy" was.

Objective: To examine the evidence behind adaptation energy and the importance this concept has in the understanding of the GAS. In addition, we review relevant applications of adaptation energy in the understanding of adaptations to resistance exercise.

Design \& Methods: The experimental work of Hans Selye and sports science literature applying his findings was reviewed.

Results/Conclusions: The concept of adaptation energy was mentioned in early publications linking Selye's GAS to resistance exercise, however, modern applications appear to disregard his experiments (rodent studies) and his mechanistic explanations (adaptation energy). It seems unlikely that adaptation energy can explain adaptation and acute responses to exercise. Instead, the concept of adaptation energy appears to share similarities with some theories of aging. Overall, it is unclear if "adaptation energy" exists and if it warrants further discussion to help understand its application.
\end{abstract}

(Journal of Trainology 2020;9:66-70)

Key words: General Adaptation Syndrome a Adaptation Energy a Hans Selye a Adaptation a Resistance Exercise

\section{INTRODUCTION}

In the early 1900 s a researcher by the name of Hans Selye conducted a series of rodent studies examining the stress response to lethal and sub-lethal doses of different drugs (e.g., morphine, atropine), and stimuli (e.g., temperature, excessive exercise). ${ }^{1}$ Selye noted a repeatable series of adaptations and responses following these stressors which became known as the general adaptation syndrome (GAS). Hans Selye's experimental findings have been applied to different fields, and have gained considerable influence in the field of strength and conditioning. For example, Selye's GAS has been applied to resistance exercise and used to help explain adaptation (i.e., changes in muscle size and strength). ${ }^{2-4}$ Despite the GAS having a large influence in the field of strength and conditioning, Selye's underlying mechanism, (adaptation energy) used to explain the responses he observed is rarely discussed. The term "adaptation energy" was first mentioned by Hans Selye in 1938 in an attempt to explain intensified symptoms of the alarm reaction and the stage of exhaustion in a group of fasted rats. ${ }^{5}$ The concept of adaptation energy is critical to the understanding of the GAS and is the hypothesized mechanism explaining why death was always the end result of the GAS (represented by the exhaustion phase).

Selye described the GAS as a "chronologic development of the response to stressors when their action is prolonged" 6 which consists of the following three stages: the alarm reaction, the stage of resistance and the stage of exhaustion.
Alarm reaction tended to occur 6-48 hours after the initial injury and its symptoms included, but were not limited to, thymus atrophy and adrenal hyperplasia. ${ }^{7}$ These symptoms would disappear during the resistance stage despite continuous exposure to damaging agents and reappear during the exhaustion stage, when the organism would eventually die. ${ }^{1}$ In 1938, Selye published an article in Nature where he summed up GAS in a simplified manner:

\begin{abstract}
"Animals continuously exposed to a uniform damaging stimulus (a drug, exposure to cold, excessive muscular exercise, etc.) at first display the symptoms of the 'alarm reaction' and later pass into a resistant phase; sooner or later, however, the power of resistance is exhausted and the symptoms reappear" 5 .
\end{abstract}

Selye's 1938 publication in Nature provided the first insight into adaptation energy. Selye introduced the idea that reappearance of alarm symptoms in the third stage of GAS supports the concept that an organism depends on "a special hitherto unrecognized type of energy". Selye proposed that an organism possesses a finite amount of adaptation energy and its amount depends largely on genetic factors. ${ }^{8}$ From his perspective, an organism could adapt to a given stimulus, but only at the expense of depleting their energy reserve. This would suggest that adaptation energy is like a fuel tank on a car. Each individual is born with one "fuel tank" to which

Received September 27, 2020; accepted December 29, 2020

From the USF Muscle Lab, Exercise Science Program, University of South Florida, Tampa, FL, USA (E.V., R.K., S.L.B.)

Communicated by Takashi Abe, PhD

Correspondence to: Dr. Samuel L. Buckner, 4202 E. Fowler Ave. PED 214, Tampa, Florida, 33620-8600

Email: slbuckner@usf.edu

Journal of Trainology 2020;9:66-70 @2012 The Active Aging Research Center

http://trainology.org/ 
they are unable to add additional fuel (i.e., adaptation energy). Once this reserve is depleted, the organism would die. Interestingly, Selye wasn't consistent in his definitions of adaptation energy which he notes himself by admitting that 30 years later, he still has no precise concept for what this energy might be. ${ }^{9}$

The purpose of this paper is to examine the evidence behind adaptation energy and the importance this concept has in the understanding of the general adaptation syndrome. In addition, we will discuss applications of adaptation energy in the context of resistance exercise. Particularly, how adaptation energy was discussed in early adoptions of Selye's GAS to sports science, but forgotten as the concept became accepted. Finally, we will propose a context in which this concept may have stronger application and explore other applications of adaptation energy. Although adaptation energy is an abstract mechanism to explain the stress response observed by Selye, it seems to share characteristics with some theories of ageing. In addition, adaptation energy may have some application in medicine.

\section{Experimental Evidence For Adaptation Energy}

Adaptation energy was first proposed by Selye as a working hypothesis in order to explain the stage of exhaustion that results in the loss of adaptation and death following exposure to various noxious agents (e.g., morphine, atropine, formaldehyde) in rodents. The "general" aspect of the general adaptation syndrome was the finding that all stressors resulted in a similar endpoint (death) as long as the dose of the stressor was "toxic". Considering the organisms inability to infinitely withstand chronic stress, Selye developed the concept of "adaptation energy". The evidence for this is provided in an experiment that included 5 groups of rats (24 rats in each group) who were adapted to either morphine, adrenaline, atropine, muscular exercise, or cold exposure. ${ }^{1}$ Rodents were "adapted" to the stimulus through gradually increasing the dose of the damaging agent until a full alarming dose (a dose that would typically initiate the alarm stage of the GAS) was achieved. Since the rodents have been gradually habituated to the stimulus, the rodents would "resist" the stimulus without showing systems of an alarm reaction (thymus involution). Once the full alarming dose was achieved, Selye separated each group into smaller groups of 6 rats and exposed these groups to either full alarming dose of the same stimuli they were adapted to or a full alarming dose of a different toxic agent. ${ }^{1}$ Additionally, Selye included a control group that was exposed to a full alarming dose of each of the stimuli mentioned above without adapting them to the stimulus. ${ }^{1}$ Selye discovered that pretreated animals experienced no ill-effects when exposed to the full alarming dose of the same stimuli. ${ }^{1}$ For example, non pre-treated rodents died within 24 hours following a fully alarming dose of atropine, yet survived a fully alarming dose if pretreated with the same agent. ${ }^{1}$ Furthermore, non-pretreated animals (control group) survived longer than the animals adapted to other stimuli. Using a similar example, rodents pre-treated with adrenaline died within 12 hours following exposure to a fully alarming dose of atro- pine. ${ }^{1}$ This finding led Selye to believe that adaptation to a certain stimuli occurs at the cost of "adaptation energy". When animals are adapted to a certain stimuli, they lose the ability to adapt to a stimuli of a different type. In short, he speculated that they had exhausted their stores of adaptation energy.

Considering that adaptation energy is an ill-defined mechanistic explanation for the GAS, Hans Selye considered the GAS itself as evidence for adaptation energy. However, it is important to note that the stages of the GAS outlined by Selye were not exclusive to Selye. Following a series of experiments on rats kept under low oxygen tension, Giragossintz and Sundstroem observed a three-stage process that resembled Selye's GAS. ${ }^{7}$ Three stages of the process included: pre-adaptive stage, adaptive stage, and post-adaptive stage. ${ }^{10}$ The postadaptive stage occurred following prolonged exposure to a low-pressure environment and resulted in exhaustion (i.e., death).$^{10}$ From Selye's perspective, this "exhaustion" would likely be explained as a depletion of adaptation energy. In Selye's opinion, any stressor would ultimately bring one closer to death. In addition, according to Selye's model of adaptation energy, adaptation energy can be depleted and not regained. ${ }^{9}$ Thus, any stress would produce an irreversible loss of one's ability to adapt to future stressors. Selye's views on stress have been applied to modern exercise. However, the experiments behind his hypotheses and the concept of adaptation energy are scarcely discussed.

\section{Modern Application for Adaptation Energy Influence in Strength and Conditioning}

Hans Selye's general adaptation syndrome has been very influential in the field of strength and conditioning. In 1960 Fred Wilt published an article in the Journal of Track Technique where he suggested that "prolonged and chronic exposure of the body to one specific stress will increase resistance to that stress, but at the expense of reducing non-specific resistance to other stressors". ${ }^{4}$ Wilt goes on to suggest that "any stress draws from the body's finite quantity of adaptation energy" and that the "stresses for which the body is less well adapted will make the greatest demand on the body's store of adaptation energy, and be the most apt to hasten exhaustion reactions. ${ }^{4}$ This application of Selye's data accepted the concept of adaptation energy as true, and assumed that exercise in humans would deplete an individual's "adaptation energy". Interestingly, Wilt does not discuss what adaptation energy might be physiologically or what happens when one becomes "exhausted". This may be problematic as Hans Selye himself was unable to describe what adaptation energy was. Although the mechanism remains elusive to Selye and Wilt, ${ }^{4}$ it seems unlikely that the same mechanism that explains stress and recovery from exercise would explain exhaustion and death in Selye's studies. In 1979 John Garhammer published a similar communication in the Journal of Track Technique where it was suggested that a single bout of exercise may include all three phases of the general adaptation syndrome. ${ }^{2}$ Garhammer suggests that:

"At the onset of activity one may feel uncomfortable or 
tight- this can be interpreted as the "alarm" stage of GAS. But one becomes accustomed to the activity stressor as it persists, and the body makes the required adjustments- it adapts to the stimulus. Finally, if the physical activity is prolonged one may become fatigued or exhausted with performance deteriorating. "2

Although Garhammer ${ }^{2}$ acknowledges the GAS, he does not discuss the concept of adaptation energy or how it might contribute to this process during and following exercise. In addition, authors apply the GAS to a single acute bout of exercise which is different than many other exercise interpretations of the GAS which suggest that repeated exercise bouts over time without appropriate programming and rest may lead to exhaustion. Garhammer goes on to discuss broader applications of the GAS suggesting that the "training year is composed of perhaps three to six macrocycles. Each of these is constructed with GAS in mind". ${ }^{2}$ Thus, Garhammer saw the GAS as having applications for understanding long term adaptions to an exercise stimulus in addition to relevance in the understanding of an acute exercise bout.

In 1982 Stone et al. ${ }^{3}$ published a "Theoretical Model of Strength Training" which seemed to solidify the acceptance of Hans Selye's experiments on the GAS as the theoretical framework for understanding adaptation to resistance exercise. ${ }^{3}$ The alarm phase of the GAS was defined within Selye's experiment as tissue deformation in response to various toxic stimuli. For example, the most consistent observation noted by Selye was thymus involution and adrenal hyperplasia in response to dosing a rodent with a toxic stressor (i.e., adrenaline, atropine, morphine). ${ }^{1}$ Within the exercise training literature this has been replaced with muscle damage, muscle soreness and even acute exercise fatigue. ${ }^{4}$ The resistance phase in Selye's experiments was noted as a period when the thymus and adrenal gland would return to their normal size and the organism would resist the resulting death of the toxic stressor $^{1}$. Within the training literature this phase is used to represent a period of time when the organism is able to adapt to an exercise stimulus (i.e., when muscle size and strength adaptations occur). ${ }^{3}$ Finally, the exhaustion phase in Selye's experiments was represented by death of the organism in response to continued exposure to the toxic stimuli. ${ }^{1}$ According to Selye, this death was due to a depletion of adaptation energy and the rodents inability to continue to adapt. ${ }^{1}$ Within the exercise literature this is represented by overtraining and exhaustion. ${ }^{3}$ It is thought that if the stress of exercise is not managed properly (i.e., periodization for proper stress management) that an individual would be at risk of "exhaustion". ${ }^{3}$ The phases of the GAS according to Selye and according to the field of strength and conditioning are presented side-byside in table 1. Although this application has been well accepted within the field of strength and conditioning, Hans Selye's model suggested that adaptation energy can be depleted and not recovered. Seyle defined the general adaptation syndrome as "the sum of all non-specific, systemic reactions of the body which ensue upon long continued exposure to stress." ${ }^{11}$ However, he clarified that the GAS "is distinct from the specific adaptive reactions, such as the development of the musculature following prolonged physical exercise, the allergic and immunologic phenomena elicited by foreign proteins or microorganisms, etc". ${ }^{11}$ Selye did not believe that the GAS explained adaptation to muscular exercise. However, if true, his model would suggest that exercise would bring one closer to death via the irreversible energy cost of adaptation. We are unaware of any concept within strength and conditioning that would support this notion.

There appears to be a lack of congruency amongst Selye's concept of adaptation energy with what happens in response to exercise (Table 1). Specifically, the adoption of the GAS by strength and conditioning seemed to simply replace Selye's phases (alarm, reaction and exhaustion) with what happens during exercise (Table I) without considering the underlying physiology or the speculated mechanisms. However, it is likely that Selye's experiments have some modern relevance. The subsequent sections will provide what might be more appropriate applications of Selye's findings in order to better understand the concept of adaptation energy.

\section{Aging - The Depletion of Adaptation Energy?}

Aging is represented by changes in tissues and organs of the body and is correlated with the loss of functional capacity at the molecular, cellular, tissue, and organ levels. ${ }^{12}$ A number of theories of aging have been proposed to explain why we age and what controls human lifespan, but none of these theories are yet to fully explain the mechanisms of aging. ${ }^{12,13}$ In his later work, Selye attempted to explain aging by linking it

Table 1 Selye's experiments and corresponding strength and conditioning application

\begin{tabular}{|c|c|c|}
\hline & Hans Selye's Experiments & Strength and Conditioning Application \\
\hline Alarm Reaction & $\begin{array}{l}\text { Thymus Involution and Adrenal Hyperplasia in response to } \\
\text { a toxic stressor. }\end{array}$ & $\begin{array}{l}\text { Muscle damage and soreness resulting from exposure to } \\
\text { exercise. }\end{array}$ \\
\hline Resistance & $\begin{array}{l}\text { Symptoms of alarm reaction disappear (i.e., thymus involu- } \\
\text { tion and adrenal hyperplasia) despite continued treatment } \\
\text { with the damaging stressor. }\end{array}$ & $\begin{array}{l}\text { Adaptation to an exercise stimulus. This is typically rep- } \\
\text { resented by increased muscle size and increased muscle } \\
\text { strength. }\end{array}$ \\
\hline Exhaustion & Death of the Organism & Overtraining \\
\hline Role of Adaptation Energy & $\begin{array}{l}\text { Once "Adaptation Energy" is depleted, the organism loses } \\
\text { its ability to adapt and dies. }\end{array}$ & $\begin{array}{l}\text { Adaptation energy is managed through periodization to } \\
\text { avoid overtraining. }\end{array}$ \\
\hline
\end{tabular}

Table 1 displays stage of the general adaptation syndrome and corresponding phenomenon represented in either Hans Selye's experiments or strength and conditioning application. 
to the concept of adaptation energy and the three stages of GAS to the ageing process. ${ }^{14}$ According to Selye, alarm reaction is similar to our childhood with its low resistance, the stage of resistance is correlated with our adulthood and increase in resistance, and the stage of exhaustion is represented by senility and the loss of an organism's ability to adapt. ${ }^{14}$ This application of adaptation energy may provide a better application of Selye's work as his experimental findings share some similarities with the wear and tear theory of aging and the rate of living theory of aging.

The wear and tear aging theory was first introduced by a German biologist August Weismann in $1882 .{ }^{15,13}$ It suggested that cells and tissues of an organism consist of vital parts that tend to wear out with time, just like car parts. ${ }^{13}$ In Weismann's opinion, parts of the human's body wear out with time and eventually kill the person. ${ }^{13}$ Interestingly, Selye proposed a similar idea stating that he never met a person who died from old age. ${ }^{14}$ He suggested that death occurs when one vital part of the body becomes worn out in contrast to the rest of the body, no matter the amount of adaptation energy we have available. ${ }^{14}$ Similar to Weismann, Selye compared our bodies to a machine that eventually wears out even if it still has enough fuel (adaptation energy). ${ }^{14}$ In Selye's opinion, life represents a biological chain that holds our parts together and when one part breaks then our parts can no longer be held together and death ensues. ${ }^{14}$ Although it is unclear whether damage described in the wear and tear theory of aging is similar to the damage in Selye's experiments, both were nonreversible stressors that brought one closer to death. Not only did Selye believe that adaptation energy can be used to describe the quantity of our lives, but also the quality of life. Selye suggested:

"At birth, each individual inherited a certain amount of adaptation energy. He can draw upon this capital thriftily for a long but monotonously uneventful existence, or he can spend it lavishly in the course of a stressful, intense, but perhaps more colorful and exciting life". ${ }^{9}$

From Selye's perspective living a life with more experience may enrich our lives, but ultimately deplete us of adaptation energy. Selye's concept of "adaptation energy" also shares many parallels with the "rate of living" theory of ageing. As originally proposed, this theory suggested that "the duration of life of an organism is dependent upon the exhaustion of a fixed quantity of a vital substance at a rate proportional to the metabolic rate". ${ }^{16}$ Herein, a genetically determined metabolic potential and rate of metabolism are both believed to govern the length of life. ${ }^{16}$ Macarthur and Ballie provide support for this theory when examining the duration of life amongst Daphnia maintained at $8^{\circ}, 10^{\circ}, 18^{\circ}$, and $28^{\circ}$ C..$^{17}$ Authors found that longevity had an inverse relationship with temperature. ${ }^{17}$ In addition, Macarthur and Ballie found that the duration of life varies inversely with the intensity of the metabolism. ${ }^{18}$ At all normal temperatures and in both sexes the Daphnia had nearly the same total number of heart beats ( 15,400,000 total beats). The authors suggest that the organ- ism appears to receive not a definite number of days, but rather a "specific sum of total vitality" (measured through heart beats). ${ }^{18}$ Elevation of temperature from $8^{\circ}$ to $28^{\circ}$ increased the heart rate by $412 \%$ and shortened the lifespan by $423 \%$. Authors found that an acceleration of metabolic rates was always associated with a very nearly proportionate decrease in duration of life. ${ }^{18}$ These experiments appear to share characteristics with Hans Selye's theories on adaptation energy. What Macarthur and Ballie refer to as "Vitality", Selye might call "adaptation energy". In both models, when there was a depletion of these ill-defined resources, death would ensue. Although the concept of adaptation energy still lacks defining characteristics, it attempts to explain death in a similar manner as the rate of living theory of aging.

\section{Other Applications of Adaptation Energy}

Similar to the field of resistance training, Occupational Therapy has adopted the concept of adaptation energy to help explain the concept of occupational adaptation. Occupational adaptation theory is a theory within occupational therapy that considers the person, the occupational environment, and the interaction of the two as they come together in occupation". 19 Within this field adaptation energy has been described as the energy that "fuels" the adaptive process. ${ }^{20}$ Schkade and Schultz explain that adaptation energy has implications for having a balanced lifestyle, suggesting that by varying activities among work, leisure, and self-maintenance can help an individual operate more efficiently. ${ }^{19}$ Schkade and Schultz interpret "adaptation energy" as a finite resource, but suggest that it is not like a fuel tank. ${ }^{20}$ Instead, authors compare adaptation energy to the number of neurons in the human body (not small, but bounded). ${ }^{20}$ Most interestingly, Schkade and Schultz acknowledge that adaptation energy is an abstract construct and express that it is applied quite differently (compared to Selye's work) in the field of occupational adaptation. ${ }^{20}$

Bernard Goldstone wrote on what might be considered the physicians perspective on adaptation energy. ${ }^{21}$ Gladstone notes how physicians are interested to know how patients "struggling with a disease will react to an additional stimulus". Goldstone discusses that adaptations to drugs such as morphine and alcohol can occur with prolonged use. Interestingly, an individual can tolerate more of the drug; however, with this tolerance general health is "enfeebled". 22 Regarding adaptation energy, Goldstone rejects Selye's view that creatures are born with a fixed quantity of adaptation energy, embracing the possibility of both spending and acquiring adaptation energy.

In the last quarter of the $20^{\text {th }}$ century a Soviet school performed a modification of Hans Selye's GAS and Adaptation Energy concept for the medical and training purposes. They used antistressor reactions in order to increase resistance of an organism even in the most stressful situations. ${ }^{23}$ These reactions were used to help people recover from illnesses and improve defense of their organism against harmful factors of different nature like radiation, exertion, emotional factors and factors of aging. They stated that “вызывая 
целенаправленную нужную адаптационную реакцию организма на определенном уровне реактивности, можно подойти к управлению резистентностью организма" 23 which roughly translates to English as a possibility of managing an organism's resistance when a targeted specific adaptation reaction is caused. Additionally, reaction of an organism was considered a way of adapting to constantly changing environment. Garkavi et al. ${ }^{23}$ emphasized that adaptation reactions of an organism support a dynamic constant of internal environment and keep all organs and systems functioning. They equated the terms "defense," "adjustment," and "adaptation" even in those cases when adaptation reaction consists of damaging elements. Hence, it's plausible to suggest that since damaging reactions lead to adaptation and adaptation is equal to defense... damaging reactions create some sort of defense mechanism in an organism helping its organs and systems function. Thus, similar to Goldstone, ${ }^{22}$ the Soviet's acknowledged that understanding alarm reactions may help to understand one's ability to withstand different treatments. However, even in medicine, adaptation energy remains an elusive concept. Nevertheless, the work of Selye and Goldstone have been reviewed by biophysicists and included in different models, such as the top down model provided by Gorban et al. ${ }^{24}$ for understanding non-specific adaptation processes. ${ }^{24}$ Thus, despite being poorly defined, adaptation energy may be a quantifiable construct.

\section{CONCLUSIONS}

Despite being paramount to explaining his experimental findings, Selye was inconsistent in defining what "adaptation energy" was. He first referred to adaptation energy as a limited resource that, when depleted, makes it impossible to adapt. ${ }^{1}$ Several years later, he went on to compare adaptation energy to an "inherited fortune" from which one could make withdrawals, but he wasn't able to find evidence that one could make additional deposits to this fortune. ${ }^{25}$ Contradicting himself, Selye hypothesized that, similar to a good night's sleep after a stressful day, a few weeks of restful holidays might restore our adaptation energy very close to what it was before. ${ }^{25}$ In one of his later books, Selye went as far as to call adaptation energy "a serum" that could be transmitted from one living being to another while regenerating the adaptation energy to some extent. ${ }^{9}$ Despite these inconsistent definitions, Selye described adaptation energy as "something different from the caloric energy we receive from food" and admitted that he doesn't have a precise concept of what this energy might be. ${ }^{9}$ The concept of adaptation energy was mentioned in early publications linking Selye's GAS to resistance exercise, ${ }^{4}$ however, modern applications appear to disregard his experiments ${ }^{26}$ (rodent studies) and his mechanistic explanations (adaptation energy). Although his data and explanations appear to share similarities with theories of aging, and appear to have potential application in medicine it is unclear if "adaptation energy" exists as a kind of energy.

\section{CONFLICT OF INTEREST}

The authors have no conflicts of interest relevant to the content of this article.

\section{REFERENCES}

1. Selye H. Experimental Evidence Supporting The Conception of "Adaptation Energy". Am J Physiol. 1938;123;3:758-765.

2. Garhammer J. Periodization of strength training for athletes. Track Tech 1979;73:2398-2399.

3. Stone MH, O'Bryant H, Garhammer J, McMillan J, Rozenek R. A Theoretical Model of Strength Training. Strength Cond J 1982;4;4:36-39.

4. Wilt F. Stress and Training.". Track Technique 1960;1;6:1-16.

5. Selye H. Adaptation energy. Nature 1938;141;3577:926-926.

6. Selye H. Forty years of stress research: principal remaining problems and misconceptions. Can Med Assoc J 1976;115;1:53-56.

7. Selye H. A syndrome produced by diverse nocuous agents. 1936. $J$ Neuropsychiatry Clin Neurosci 1998;10;2:230-231.

8. Selye H. Stress and the general adaptation syndrome. Br Med $J$ 1950; $1 ; 4667: 1383-1392$.

9. Selye H. The stress of life. New York: McGraw-Hill; 1978. xxvii, 515.

10. Giragossintz G, Sundstroem E. Cortico-adrenal insufficiency in rats under reduced pressure. Proceedings of the Society for Experimental Biology and Medicine 1937;36;4:432-434.

11. Selye $\mathrm{H}$. The general adaptation syndrome and the diseases of adaptation. Journal clin endocrinol Metab. 1946;6;2:117-230.

12. Fedarko NS. Theories and mechanisms of aging. Geriatric Anesthesiology: Springer; 2018. p 19-25.

13. Jin K. Modern biological theories of aging. Aging Dis. 2010;1;2:72.

14. Selye H. Stress, aging and retirement. J Mind Behav. 1980:93-110.

15. Weismann A. Schriften über Vererbung und verwandte Fragen: Ueber dir Dauer des Lebens.-Ueber die Vererbung.-Ueber Leben und Tod.-Die Continuität des Keimplasmas als Grundlage einer Theorie der Vererbung.Die Bedeutung der sexuellen Fortpflanzung für die Selektions-Theorie.Ueber die Zahl der Richtungskörper und über ihre Bedeutung für die Vererbung.-Ueber die Hypthese einer Vererbung von Verletzungen: Gustav Fischer; 1882

16. Sohal R. The rate of living theory: a contemporary interpretation. Insect aging: Springer; 1986. p 23-44.

17. MacArthur J.W., Baillie W.H.T. Metabolic activity and duration of life. $J$ Exp Zool S 1929;3:221-268.

18. MacArthur J, Baillie W. Metabolic activity and duration of life. II. Metabolic rates and their relation to longevity in Daphnia magna. Journal of Experimental Zoology 1929;53;2:243-268.

19. Schkade JK, Schultz S. Occupational adaptation: Toward a holistic approach for contemporary practice, part 1. Am J Occup Ther 1992;46;9: 829-837.

20. Schkade J, Schultz S. Occupational Adaptation in Perspectives, Ch. 7 in: Perspectives in Human Occupation: Participation in Life, By Paula Kramer, Jim Hinojosa, Charlotte Brasic Royeen. Lippincott Williams \& Wilkins, Baltimore, MD; 2003

21. Goldstone B. The general practitioner and the general adaptation syndrome. S Afr Med J 1952;26;6:106-109; concl.

22. Goldstone B. The General Practitioner and the General Adaptation Syndrome. S Afr Med J 1952;26:88-92.

23. Гаркави Л, Квакина Е, Кузьменко Т. Антистрессорные реакции и активационная терапия. М.: “ИМЕДИС”. 1998.

24. Gorban AN, Tyukina TA, Smirnova EV, Pokidysheva LI. Evolution of adaptation mechanisms: Adaptation energy, stress, and oscillating death. $J$ Theor Biol. 2016;405:127-139.

25. Selye H. Stress without distress. Brux Med 1976;56;5:205-210.

26. Buckner SL, Mouser JG, Dankel SJ, Jessee MB, Mattocks KT, Loenneke JP. The General Adaptation Syndrome: Potential misapplications to resistance exercise. J Sci Med Sport. 2017;20;11:1015-1017. 